\title{
Research on the Tourism Efficiency in Guangxi —— Based on DEA-Malmquist Model
}

\author{
Li Wenhua ${ }^{1, *}$ \\ ${ }^{1}$ College of Tourism \& Landscape Architecture, Guilin University of Technology, Guilin 541004, China
}

\begin{abstract}
Taking 14 cities in Guangxi Zhuang Autonomous Region, where the typical ethnic minorities gather in harmony in China, as the research objects, the DEA-Malmquist model is used to dynamically analyze the tourism efficiency of 14 cities in Guangxi from 2004 to 2018. The results show that the total factor productivity of the overall tourism industry in Guangxi Zhuang Autonomous Region is unevenly distributed, and the regional gap is large, but the overall growth trend is maintained; the changes in the technical progress index and the total factor productivity change index are generally consistent, and the improvement of technological progress is the most effective way to promote the efficiency growth of tourism in Guangxi Zhuang Autonomous Region. The main driving force are economic development level, geographic location, tourism development policy, tourism resource endowment and other factors have varying degrees of influence on the tourism efficiency in Guangxi. Finally, this article draws relevant conclusions based on the results of empirical analysis, and put forward relevant suggestions for the development of tourism in Guangxi.
\end{abstract}

\section{Introduction}

Under the development of the new normal economy, tourism, as a driving force to promote economic growth, has become a strategic pillar industry in our country. Tourism efficiency is an important yardstick to measure the ability of tourism economic entities to utilize resources and maximize the total surplus of all stakeholders[1], tourism efficiency refers to the property of maximizing output and maximizing the total surplus of all stakeholders in the development process of tourism in a specific time frame[1]. It is essentially an objective economic phenomenon[2]. The earliest domestic and foreign research on the efficiency of the tourism industry began in the field of tourism hotels. The research on the efficiency of the tourism industry was carried out in foreign countries earlier than in China. Morey and Dittman were the first to use the DEA-CCR model to study 54 private chain hotels in the United States, and concluded that the average efficiency of the hotel industry in the United States is relatively high (89\%)[3]. Domestically, Peng Jianjun and Chen Hao used the DEA-CCR model to study the efficiency of star-rated tourist hotels in Zhejiang, Jiangsu and Shandong provinces, and found that overall the efficiency of tourist hotels in the three provinces is at a very high level[4].

In terms of research methods of tourism efficiency, it mainly includes parametric and non-parametric methods. The former is mostly represented by stochastic frontier analysis[5], and the latter is represented by data envelopment analysis (DEA) and improved DEA model[6]. Existing studies have conducted useful explorations on tourism efficiency, but there are insufficient studies on tourism provinces with distinctive ethnic minority characteristics. Guangxi is one of the earliest regions in my country to develop tourism on a large scale. Its tourism products are mostly traditional sightseeing tourism products. The gap between the development speed of tourism in other parts of the country and other regions of the country is gradually widening, and the problem of unbalanced development speed of tourism in cities with municipal regions as the unit is also increasingly exposed. Based on the DEAMalmquist index model, Studying the dynamic evolution process of the tourism industry and the characteristics of tourism efficiency in the cities under the jurisdiction of Guangxi Zhuang Autonomous Region can effectively promote the growth of Guangxi's tourism economy and the transformation of tourism development paths, promote the reasonable and effective allocation of tourism resources, and promote the development of tourism in Guangxi cities industry.

\section{Research methods and data sources}

\section{1 sresearch method}

The Malmquist index was first proposed by Malmquist (1953)[7], and Caves et al. (1982)[8], first used the Malmquist index to measure productivity changes. The Malmquist model can be used to calculate the average annual growth rate MI (Malmquist index) of the tourism industry efficiency in each province. If MI $>1$, it indicates 
that the total factor productivity (TFP) is positive growth; if $\mathrm{MI}<1$, it indicates that the total factor productivity is a negative growth; if $\mathrm{MI}=1$, it indicates that the total factor productivity is unchanged. MI can be decomposed into technical efficiency change index (TEC) and technical progress index (TP). The Technical Efficiency Change Index (TEC) reflects the ratio of the actual output of the tourism industry to the maximum possible output under the existing technology. If TEC $>1$, it indicates that the technical efficiency of the tourism industry has improved; if $\mathrm{TEC}<1$, it indicates that the tourism industry technology Declining efficiency. The Technological Progress Index (TP) reflects whether there is technological progress in the tourism industry of each province. If $\mathrm{TP}>1$, it means that the tourism industry has technological progress; if $\mathrm{TP}<1$, it means that the tourism industry has no technological progress. Technical efficiency change index (TEC) can be further decomposed into pure technical efficiency change index (PTEC) and scale efficiency change index (SEC). The pure technical efficiency change index (PTEC) indicates the relative change of the pure technical efficiency of the tourism industry from $\mathrm{t}$ to $\mathrm{t}+1$ under certain scale conditions. If $\mathrm{PTEC}>1$, it indicates that the pure technical efficiency of the tourism industry from $t$ to $t+1$ is relatively improved; On the contrary, it shows that the pure technical efficiency of the tourism industry from $t$ to $t+1$ period is relatively reduced. The Scale Efficiency Change Index (SEC) reflects the changes in the return to scale of the tourism industry from $t$ to $t+1$. If SEC $>1$, it means that the return on scale of the tourism industry is increasing; SEC $<1$ means that the return on scale of the tourism industry is diminishing; if $\mathrm{SEC}=1$, Indicates that the return to scale of the tourism industry remains unchanged.

\subsection{Index system}

This article divides industrial tourism efficiency indicators into input and output indicators. Input indicators are cost indicators, and expected output indicators are profit indicators. In view of the availability of data and the particularity of the DEA method, refer to Deng Hongbo, Lu Lin[3]'s urban tourism efficiency index evaluation system, and constructed the Guangxi tourism efficiency evaluation index system ( Table 1). Although the output brought by the investment in urban tourism development may not be rewarded in the current year, considering the simultaneity of the lag effect of input and output, and most of the input in the current year will inevitably affect the actual situation of most of the output in the current year, so it is ignored the impact of this lag effect on tourism efficiency [6].

Tourism input: Considering the direct and indirect employment brought about by the comprehensiveness of the tourism industry, and because most municipalities in Guangxi do not count the number of employees in the tertiary industry as an indicator, there are a large number of missing data on the number of employees in the tertiary industry, so labor input select the indicator of the proportion of employees in the tertiary industry; fixed capital investment is selected from the fixed asset investment of the tertiary industry; tourism resources are the basis for the development of tourism, and tourism brand resources (A-level scenic spots, travel agencies, star hotels) reflect the investment in tourism, so the sum of the number of A-level scenic spots, the number of travel agencies, and the number of star-rated hotels is selected as the investment indicator.

Tourism output: Scholars have different criteria for selecting tourism output indicators, but most of them use tourism income or tourist reception as output indicators[9]. Select the total tourism revenue (tourism domestic revenue + tourism foreign exchange revenue) and the total number of tourist reception (domestic tourists + inbound tourists) as tourism output.

When using the DEA method for efficiency research, it is required that the total number of decision-making units is greater than twice the sum of all input and output indicators. In this paper, the number of DMUs is 14, 3 input indicators, and 2 output indicators. And $\mathrm{DMU}=14>2 *(3+2)$, which meets the requirements.

Table 1. Efficiency Evaluation Index System of Guangxi Tourism Industry

\begin{tabular}{|c|c|c|}
\hline Target & Element & Index \\
\hline \multirow{5}{*}{$\begin{array}{l}\text { Tourism } \\
\text { efficiency }\end{array}$} & \multirow{3}{*}{$\begin{array}{c}\text { Tourism } \\
\text { investme- } \\
n t\end{array}$} & $\begin{array}{c}\text { Proportion of employees in tertiary industry } \\
\text { units (persons) }\end{array}$ \\
\hline & & $\begin{array}{l}\text { Fixed asset investment in the tertiary industry } \\
\qquad(100 \text { million yuan })\end{array}$ \\
\hline & & $\begin{array}{l}\text {, The sum of star-rated hotels (a), travel agencies } \\
\text { (a), A-level scenic spots (a) }\end{array}$ \\
\hline & \multirow{2}{*}{$\begin{array}{l}\text { Tourism } \\
\text { output }\end{array}$} & Total tFourism revenue (100 million yuan) \\
\hline & & Total number of tourists (person) \\
\hline
\end{tabular}

\subsection{Data Sources}

The data involved in the input and output indicators for the efficiency evaluation of Guangxi's tourism industry in this article are all derived from the 2005-2019 China City Statistical Yearbook, Guangxi Statistical Yearbook and the municipal national economy of Guangxi municipalities from 2004 to 2018. And Social Development Statistical Bulletin. Among them, the proportion of employees in tertiary industry units comes from the China City Statistical Yearbook; fixed investment in the tertiary industry has not been counted for some years in some cities, so this article uses fixed asset investment multiplied by the tertiary industry's share of regional GDP. It is calculated that the data on the proportion of fixed asset investment and tertiary industry in the regional GDP are from the Guangxi Statistical Yearbook and China City Statistical Yearbook respectively; the number of travel agencies, the number of A-level tourist attractions, the number of star hotels, and tourism Input data such as total income and total number of tourists are all from the Guangxi Statistical 
Yearbook. It should be pointed out that the foreign exchange income from tourism in the total tourism income in 2004 and 2005 is expressed in U.S. dollars in the yearbook, so this article uses the exchange rate of RMB to USD in the Statistical Bulletin of the People's Republic of China on National Economic and Social Development to multiply the foreign exchange income from tourism. get it.

\section{Results and analysis}

The development of tourism is easily affected by factors such as internal and external environment. The volatility is relatively large, the input factors are easy to change, and the possibility of fixed returns to scale is very small. Therefore, this article selects the variable return to scale model in the DEA model for tourism. Efficiency analysis, based on the relevant raw data of the tourism input and output of the 14 municipalities in Guangxi from 2004 to 2018, through the application of DEAP2.1 software, and output-oriented, the tourism efficiency of the 14 municipalities in Guangxi from 2004 to 2018 is obtained Value (table 2) and its changes (table 3).

Table 2. The comprehensive tourism efficiency and its decomposition value of each city in Guangxi from 2004 to 2018

\begin{tabular}{|c|c|c|c|c|c|}
\hline Citys & Effch & Techch & Pech & Sech & Tfpch \\
\hline Nanning & 1.000 & 1.110 & 1.000 & 1.000 & 1.110 \\
\hline Liuzhou & 0.997 & 1.060 & 1.000 & 0.997 & 1.059 \\
\hline Guilin & 1.000 & 1.060 & 1.000 & 1.000 & 1.060 \\
\hline Wuzhou & 1.023 & 1.102 & 1.024 & 0.999 & 1.128 \\
\hline Beihai & 1.001 & 1.064 & 1.000 & 1.001 & 1.065 \\
\hline Fangcheng- & 1.011 & 1.057 & 0.991 & 1.021 & 1.069 \\
\hline gang & 1.028 & 1.103 & 1.026 & 1.003 & 1.135 \\
\hline Qinzhou & 1.013 & 1.092 & 1.011 & 1.002 & 1.106 \\
\hline Guigang & 1.000 & 1.109 & 1.000 & 1.000 & 1.109 \\
\hline Yulin & 1.019 & 1.103 & 1.018 & 1.001 & 1.124 \\
\hline Baise & 1.000 & 1.096 & 1.000 & 1.000 & 1.096 \\
\hline Hezhou & 1.008 & 1.068 & 1.007 & 1.000 & 1.076 \\
\hline Hechi & 1.000 & 1.033 & 1.000 & 1.000 & 1.033 \\
\hline Laibin & 1.000 & 1.040 & 0.982 & 1.018 & 1.040 \\
\hline Chongzuo & 1.007 & 1.078 & 1.004 & 1.003 & 1.086 \\
\hline Mean & & &. & \\
\hline
\end{tabular}

Table 3. Changes in the efficiency of the tourism industry in Guangxi's municipalities from 2004 to 2018

\begin{tabular}{|c|c|c|c|c|c|}
\hline Years & effch & Techch & Pech & Sech & Tfpch \\
\hline $\mathbf{2 0 0 4 - 2 0 0 5}$ & 1.038 & 0.986 & 1.000 & 1.038 & 1.023 \\
\hline
\end{tabular}

\begin{tabular}{|c|c|c|c|c|c|}
\hline $\mathbf{2 0 0 5 - 2 0 0 6}$ & 0.975 & 1.032 & 0.989 & 0.986 & 1.006 \\
\hline $\mathbf{2 0 0 6 - 2 0 0 7}$ & 1.013 & 1.013 & 0.998 & 1.015 & 1.027 \\
\hline $\mathbf{2 0 0 7 - 2 0 0 8}$ & 0.947 & 0.983 & 1.037 & 0.913 & 0.930 \\
\hline $\mathbf{2 0 0 8 - 2 0 0 9}$ & 1.017 & 0.954 & 1.011 & 1.006 & 0.970 \\
\hline $\mathbf{2 0 0 9 - 2 0 1 0}$ & 1.022 & 1.079 & 0.986 & 1.036 & 1.102 \\
\hline $\mathbf{2 0 1 0 - 2 0 1 1}$ & 1.003 & 1.065 & 0.989 & 1.015 & 1.068 \\
\hline $\mathbf{2 0 1 1 - 2 0 1 2}$ & 1.025 & 1.070 & 1.044 & 0.982 & 1.097 \\
\hline $\mathbf{2 0 1 2 - 2 0 1 3}$ & 1.025 & 1.242 & 1.058 & 0.969 & 1.274 \\
\hline $\mathbf{2 0 1 3 - 2 0 1 4}$ & 0.966 & 1.111 & 1.000 & 0.966 & 1.073 \\
\hline $\mathbf{2 0 1 4 - 2 0 1 5}$ & 1.004 & 1.081 & 0.990 & 1.014 & 1.086 \\
\hline $\mathbf{2 0 1 5 - 2 0 1 6}$ & 1.002 & 1.182 & 0.985 & 1.038 & 1.208 \\
\hline $\mathbf{2 0 1 6 - 2 0 1 7}$ & 0.999 & 1.168 & 0.988 & 1.012 & 1.168 \\
\hline $\mathbf{2 0 1 7 - 2 0 1 8}$ & 1.048 & 1.072 & 0.986 & 1.063 & 1.229 \\
\hline Mean & 1.007 & 1.078 & 1.004 & 1.003 & 1.086 \\
\hline
\end{tabular}

\subsection{Distribution characteristics of tourism efficiency in various municipalities in Guangxi}

The Table 2 shows that the production efficiency of Guangxi's tourism industry from 2004 to 2018 has the following distribution characteristics; first, the change in technical efficiency generally decreases from southeast to northeast, with Qinzhou City located in the south being the highest, followed by Wuzhou City, among the 14 lower-level cities. Only Hechi, Fangchenggang, Guigang, Baise, Wuzhou and Qinzhou reached the average. Although Nanning is the capital of Guangxi and is located in the central part of Guangxi, its technical efficiency change index is lower than that of the surrounding municipalities. Liuzhou City, located in northwestern Guangxi, is the lowest, not reaching 1 . The second is that the technological progress index is low in the north and south. Low flaky distribution in the west and east. The technological progress index of the 14 municipalities under the jurisdiction of the autonomous region are all greater than 1 , the capital Nanning is the highest, and Laibin in the middle is the lowest; third, the distribution of pure technical efficiency changes is low in the southwest and high in the southeast, and the overall difference between the cities under each jurisdiction is not much. Only Chongzuo and Fangchenggang are low, which is less than 1. Fourth, scale efficiency changes are characterized by high southwest and low northeast. Only three municipalities (Qinzhou, Chongzuo, and Fangchenggang) reach the average value, except for Chongzuo. City and Fangchenggang City have relatively high scale efficiency changes, while the other provincial cities are all less than 1.02. Fifth, the changes in the total factor productivity index and the technological progress index are roughly similar, and the total factor productivity change assistance of all municipalities is 
greater than 1. Qinzhou City is the highest and Laibin City is the lowest, with a difference of more than 0.1 . On the whole, the distribution of total factor productivity is uneven and the regional gap is large.

\subsection{Changes in Guangxi tourism efficiency}

The Table 3 shows that the changes in the efficiency of Guangxi's tourism industry from 2004 to 2018 showed the following characteristics: First, the overall change in TEC was not large and relatively stable; second, the TP was excluded from 2004-2005, 2007-2008, and 2008Except for the three periods in 2009 that were less than 1, other periods were greater than 1. Among them, the progress in the two periods of 2012-2013 and 2015-2016 was obvious, indicating that Guangxi's tourism industry except for 2004-2005, 2007-2008, 2008-2009 the trend of technological progress outside the three periods of the year is obvious; third, the PTEC is less than 1 in more than half of the periods, and only the two periods of 2011-2012 and 2012-2013 have a significant increase, and the trend of changes throughout the period is not large ; Fourth, the SEC is less than 1, except for the five periods of 2005-2006, 2007-2008, 2011-2012, 20122013, and 2013-2014 that are less than 1, other periods are greater than 1 , that is, only 2005- The five time periods of 2006, 2007-2008, 2011-2012, 2012-2013, 2013-2014, the tourism industry showed diminishing returns to scale, and the other time periods showed increasing returns to scale, and the entire time period showed an up-and-down oscillating evolution, although the overall improvement has been achieved, it lacks stability; Fifth, the TFP is less than 1 in the two periods of 2007-2008 and 2008-2009, which is manifested as a decrease in production efficiency. The other periods are all greater than 1, and the production efficiency is all different. Increase, and the increase in the two periods of 2012-2013 and 2015-2016 is very obvious. Generally speaking, technological progress dominates the efficiency of tourism production in Guangxi, and the changes in the TEC of Guangxi tourism industry are highly consistent with the changes in SEC.

\subsection{Analysis of the reasons for efficiency differences}

First of all, the difference in the level of economic development of each city has an important impact on the efficiency of the tourism industry. Generally speaking, the higher the level of regional economic development, the more sufficient financial support is provided for the development of the tourism industry, which will help to build a more complete infrastructure and service facilities. Form a good operating management system and appropriate operating philosophy to attract more high-quality human resources. Secondly, superior location conditions are also an important factor affecting the development of tourism. The geographical position is superior, the transportation is convenient, the tourist accessibility is high, the attraction to tourists is stronger, and it is easier to attract the entry of external resources, information and technology. Third, the formulation of relevant tourism development policies can provide strong support for human, material and financial resources, so as to optimize the allocation of tourism resources and improve the level of development of the tourism industry. For example, Nanning, the capital city of Guangxi, Cities along the coast and close to the border such as Baise, Chongzuo, Qinzhou, Beihai, etc., these cities have superior geographical locations, complete transportation networks, and rich tourism resources. Therefore, the efficiency of the tourism industry has reached a relatively high level. Finally, the endowment of tourism resources, that is, the type, characteristics, richness and distribution of tourism resources, and the degree of development and protection of tourism resources. These factors affect the attraction of tourism resources to tourists and the development benefits of tourism business scale. Affected the efficiency of the tourism industry[10], such as Guilin, Beihai, Fangchenggang, Chongzuo etc.

\section{Conclusion and discussion}

This paper uses the DEA-Malmquist model to measure the efficiency of the tourism industry in various municipalities in Guangxi and analyzes its spatial differences and causes. The research conclusions are as follows:

1. Spatial characteristics: The spatial distribution of TFP is unbalanced, and the regional gap is large. The change in TEC gradually decreases from the southeast to the northeast; the changes in the TP and the TFP change index are generally consistent, showing a patchy distribution of low in the north and south, and high in the west and east; the distribution of PTEC changes is low in the southwest and high in the southeast The characteristics of SEC are high in the southwest and low in the northeast.

2. Time characteristics: The overall TEC has not changed much and is relatively stable; except for the three periods of 2004-2005, 2007-2008, and 2008-2009, the trend of technological progress in the rest of the period is obvious; the trend of PTEC is not large; the return on scale of the tourism industry has oscillated up and down throughout the entire period. Although the overall improvement has been achieved, it lacks stability. Except for the reduction in tourism production efficiency in the two periods of 2007-2008 and 2008-2009, the tourism production efficiency in other periods has been improved.

3. Reasons for formation: The change of TEC and the change of SEC are highly consistent, and technological progress dominates the efficiency of tourism production in Guangxi. In addition, factors such as the level of economic development, geographic location, tourism development policies, and tourism resource endowments have varying degrees of influence on the tourism efficiency in Guangxi.

Based on the above conclusions, to improve the tourism efficiency in Guangxi, measures should be taken from the following aspects: First, in the era of big data, we should increase investment, provide financial support, 
improve tourism technical facilities, innovation, and "create smart tourism "Promote the healthy development of the tourism industry; the second is to develop tourism in accordance with local conditions, and local cities will develop suitable tourism industries based on their own resource endowments, dig deep into the connotations of regional culture, and form unique characteristics; third, rationally allocate tourism resources, develop regional linkages, and optimize resources Configure, improve efficiency, and achieve common development.

\section{Acknowledgement}

Supported by: Doctoral Research Startup Project of Guilin University of Technology Research on the Historical Geography of Guilin Traditional Gardens

\section{References}

1. K.Wang, Z.F. Huang, Y.G. Tao, Y.L. Fang, EG, 33, 161-167(2013).

2. Y.L. Fang, Z.F. Huang, F, Wang, PIG, 37, 13921404(2018).

3. R.C. Morey, D.A. Dittman, CHRAAQ, 36, 3035(1995).

4. J.J. Peng, H. Chen, TT, 2, 59-62(2004).

5. R. Oliveira, M.I. Pedro, R.C. Marques, IJOHM, 35, 59-67(2013).

6. J.G. Liu, Y. Liu, EG, 35, 190-197(2015).

7. S. Malmouist, TE, 4, 209-242(1953).

8. D.W. Caves, L.R. Christensen, W.E. Diewert, E, 50, 1393-1414(1982).

9. C.P. Barros, TE, 12, (2006).

10. H.G. Wang, J.W,Li, JOHU(NS), 4, 360-363(2004). 